\title{
Task-specific effects of d-amphetamine and blindness on BALB/cj mice
}

\author{
ROBERT S. DYER, DOUGLAS A. WELDON, and ARMEN H. THOUMAIAN \\ Department of Environmental Medicine, Johns Hopkins University \\ 615 N. Wolfe Street, Baltimore, Maryland 21205
}

\begin{abstract}
Optic enucleation increases activity in the photocell box and open field upon first exposure, but shuttlebox activity changes only occur after number of shocks/day decreases. Amphetamine did not affect open-field, photocell box, or shuttlebox activity scores when shocks were absent. In the presence of shock, with or without learning contingencies, amphetamine did increase activity.
\end{abstract}

Blindness increases open-field locomotor activity (Dyer \& Weldon, 1975) and produces marked increases in intertrial crossing during the terminal phases of shuttle avoidance learning in $\mathrm{BALB} / \mathrm{cj}$ mice (Dyer, Hammond, Weldon, \& Booker, 1975) in a way which is probably independent of recovery time following enucleation (Dyer \& Hammond, 1975). Little is known about these activity changes, except that they also occur to a lesser extent in guinea pigs (Dyer, 1971; O'Hara \& Dyer, 1974) but not in rats, hamsters, or chinchillas (Dyer et al., 1975). The present investigations were therefore carried out to further characterize the blindnessinduced changes in activity of BALB/cj mice.

Several approaches are available for further characterizing this phenomenon. The approach chosen in the present experiments was to compare blindness-induced activity changes with activity changes produced by another technique using several different measures of activity. Amphetamine was chosen as the second method for changing activity, since data relating dose to activity was available for the BALB/c strain (Davis, Babbini, Pong, King, \& White, 1974), and since other techniques for varying activity in this strain have not been reported. To prevent the study from becoming unwieldy, a decision to use one dose of amphetamine for all experiments was made. The dose chosen was near the most effective dose for producing hyperactivity in individually housed $\mathrm{BALB} / \mathrm{c}$ mice tested in a circular photocell box (Davis et al., 1974). Since the effectiveness of a given dose of amphetamine depends upon the task, and since the dose/response curve for amphetamine and activity in BALB/c mice shows only small changes even at the most effective doses (Davis et al.,

The authors wish to thank Dr. Z. Annau for helpful comments during the course of these experiments. The present address of Douglas A. Weldon is: Department of Psychology, SUNY/Buffalo, Buffalo, New York. Armen H. Thoumaian's present address is Baltimore, City Hospital, Baltimore, Maryland.
1974), some measures of activity might be unaffected by the dose chosen. A second purpose of the present study is to characterize those tasks which most effectively separate amphetamineinjected $\mathrm{BALB} / \mathrm{c}$ mice from controls.

\section{EXPERIMENT I}

\section{Method}

Design. Animals were randomly assigned to one of four groups in a 2 by 2 by 6 factorial design, with amphetamine treatment, enucleation, and days of training as the factors. The groups were composed of: (1) normal animals with saline injections (Group NS), (2) enucleated animals with saline injections (Group ES), (3) normal animals with amphetamine injections (Group NA), and (4) enucleated animals with amphetamine injections (Group EA).

Animals. Forty male BALB/cj mice, obtained from Jackson Laboratories when 5 weeks old, were used. Animals were housed individually in cages $17.8 \times 12.7 \times 10.2 \mathrm{~cm}$, and food and water were available ad lib.

Apparatus. A Lehigh Valley mouse shuttle cage (Model 146-02) was situated inside a BRS Foringer soundproof chamber. A Heath buzzer provided a CS of 3-dB intensity above background, and a Lafayette Model 5820 neon grid scrambler and Lafayette Model 5806 constant current shocker delivered a UCS of $.25 \cdot \mathrm{mA}$ constant current shock. Standard relay equipment was used to program the apparatus. In this experiment and the others reported here, illumination intensity was maintained at about $3 \mathrm{fc}$.

Surgery. All mice were anesthetized with Penthrane (methoxyflurane). The 20 animals in Groups ES and EA were then enucleated by sectioning the extraocular muscles and removing the globes. Eyelids of the operated animals were closed with sutures to prevent infection.

Procedure. Two-way training was initiated 2 days after surgery and consisted of 25 trials/day for 6 days. For each trial, the tone was presented for $10 \mathrm{sec}$, and, during the last $3 \mathrm{sec}$, shock was presented. If a response was made by crossing to the other side of the shuttlebox before the end of the trial, the trial was terminated. Intertrial intervals ranged from 15 to $90 \mathrm{sec}$ with an average of $45 \mathrm{sec}$. Responses during the first $7 \mathrm{sec}$ of CS presentation were classified as avoidances, and responses made during the intertrial intervals were classified as spontaneous crossings. An average response latency was also measured for each animal's daily 25 trials. The first trial of training began with the first shock received by the animal, in accordance with the procedure used 
by Dyer et al. (1975), to compensate for high activity levels in mice leading to initial spurious avoidances.

Animals received injections of either saline (for mice in Groups NS and ES) or d-amphetamine (for mice in Groups NA and $E A)$, in doses of $10 \mathrm{mg} / \mathrm{kg}, 30 \mathrm{~min}$ before their training sessions. The $\mathrm{d}$-amphetamine was injected in a vehicle of distilled water in a concentration of $4 \mathrm{mg} / \mathrm{cc}$.

Number of avoidances, number of spontaneous crossings, and mean response latency for each animal's daily 25 trials were recorded. Weights of each animal on the first and last days of training were also recorded to insure that any differences in performance were not due to differences in the weights of the animals.

\section{RESULTS}

Spontaneous crossing, avoidance, and response latency scores were transformed to $\log (X+1)$, $\sqrt{X+1}$, and $1 /(X+1)$ scores, respectively, so that heterogeneity of variance could be reduced (Kirk, 1968). In accordance with Keppel (1973), the tests and corrections for equality and symmetry of the covariances of the cells were not considered necessary. Analyses of variance were then performed for the three dependent variables, each being a 2 by 2 by 6 mixed design with Vision (normal vs. enucleated) and Drug (saline vs. amphetamine) as the between-group factors and Days of Training (1 through 6) as the repeated-measures factor.

Spontaneous crossing performances for the four groups across the 6 days of training are presented in Figure 1, and the saline-injected groups appear similar to those reported earlier (Dyer et al., 1975). At the beginning of training, Groups NS and ES exhibited less activity than Groups EA and NA did. As training continued, Group ES eventually increased in activity to the level of NA while Group EA decreased in activity to the level of NS. Throughout training, Group NA showed greater activity than Group NS. The triple interaction of

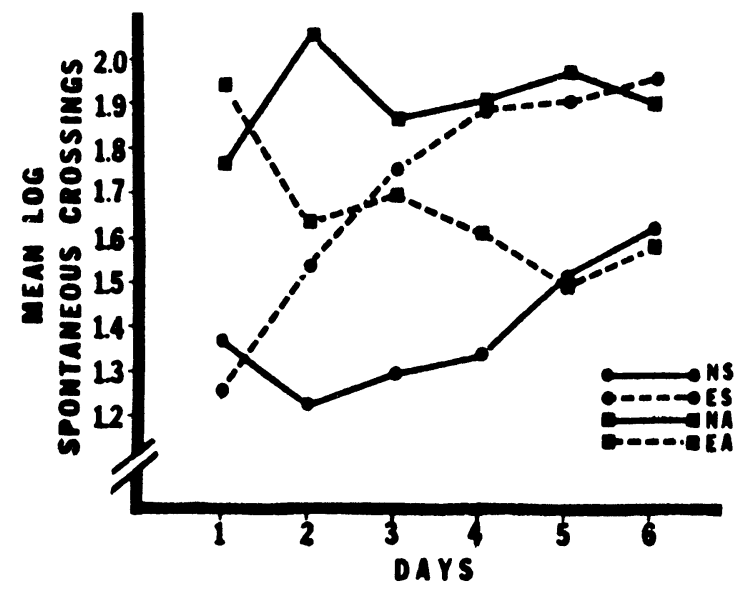

Figure 1. Mean spontaneous crossings $[\log (X+1)]$ for the four groups of Experiment I across the 6 days of training. ES = enuclested saline; EA = enucleated amphetamine; NS = normal saline; $N A=$ normal amphetamine.
Drug by Vision by Days was statistically significant $(p<.01)$, and subsequent Newman-Keuls tests (performed separately for each day) supported the descriptive statements made above.

The nature of the avoidance performance results parallel those of the spontaneous crossings, with NA animals better performers than NS animals throughout training, ES animals increasing with training to the level of NA animals, and EA animals decreasing in avoidance performance with training to the level of NS animals. The analysis of variance again revealed a statistically significant Vision by Drug by Days interaction $(p<.01)$. The post hoc comparisons supported the differences in the groups described above, with the exception of the ES-NS difference, which approached, but did not reach, statistical significance.

The results obtained by analysis of mean reciprocals of mean response latencies for the experiment correspond closely with the previous two measures.

To determine whether any effects found in the study might have been due to the weights of the animals involved, mean weights for each of the four groups were obtained for the 1 st and last days of training. Mean weight for all animals on the 1st day of training was $16.9 \mathrm{~g}$, compared with $17.9 \mathrm{~g}$ on the last day of training. The 2 by 2 by 2 analysis of variance showed only the Days factor to be statistically significant $(p<.01)$.

\section{EXPERIMENT II}

In Experiment I, differences in activity produced by amphetamine were apparent on the 1st day of training, but blindness-induced changes in activity only occurred after several days. In the present experiment, the shock and learning variables were eliminated, and animals were studied instead in a photocell box.

\section{Method}

Design. The experiment was designed in a manner identical to Experiment I, and animals were again randomly assigned to the same four groups.

Animals and surgery. In this experiment, 120 experimentally naive male mice of the BALB/cj strain were obtained, housed, fed, and operated upon as in Experiment $I$.

Apparatus. The apparatus consisted of a removable $17.8 \times 17.8$ $x 33.0 \mathrm{~cm}$ wide clear Plexiglas chamber and an external chamber containing two mounted photocell units (Clarex Model 703L) placed $11.0 \mathrm{~cm}$ apart and $1.3 \mathrm{~cm}$ from the base. Light beams divided the Plexiglas chamber into three equal.parts, and obstruction of the light beams provided a means by which activity could be measured. All interruptions of the light beams were tabulated automatically. There were four activity chambers in all, each housed in a sound-attenuating chamber equipped with a $15-\mathrm{W}$ bulb placed $68.6 \mathrm{~cm}$ above the floor, a whisper fan for circulation of air, and a one-way viewing glass.

Procedure. After a postoperative period of 2 days, one 
animal of each group was given its respective drug dose intraperitoneally. After $30 \mathrm{~min}$, each animal was placed in an apparatus and its locomotor activity tabulated over a period of $1 \mathrm{~h}$. At the end of the hour, each animal was removed to its home cage and another animal was prepared. One animal for each of the four groups was run during a specific hour of the day, over a 6-day period. The experiment was performed with several replications, and all testing occurred during the lights-on section of the 12:12 light/dark cycle. The four chambers were counterbalanced across groups so that each group had experience with each device. The internal chamber of each apparatus was rinsed with water between periods of occupation by each animal and disinfected with Septisol at the end of each day. All animals were weighed before the operations were begun and after the 6-day test period.

\section{RESULTS}

The total frequency count of light-beam interruptions for each group for each day of the 6-day period was tabulated and incorporated into the 2 by 2 by 6 factorial design (Drug Condition by Vision by Days), and analysis of variance was performed as described for Experiment I. A Tukey b test was performed on all subsequent significant effects involving a single condition with more than two variables. A graph of the mean activity scores for each group for each day is presented in Figure 2. From the graph, it appears that enucleation increased activity but that amphetamine had no effect. The analysis of variance supported the description of Figure 2, since there was a significant effect for vision $(p<.01)$ and the Vision by Days interaction $(p<.05)$, but not for the effect of drug (p > .10).

An analysis of the simple main effects was performed on the Days by Vision interaction. The activity of the enucleated groups was significantly higher than that of unoperated groups for all days. The $p$ value was $<.01$ for Days $1-4$ and reached $<.001$ for Days 5 and 6 . This change in the level of significance may account for the Days by Vision interaction.

A two-way analysis of variance was performed on the mean weight of each animal to determine if weight was a significant factor influencing animal activity. No significant differences were found between any conditions.

\section{EXPERIMENT III}

As expected, the blind animals of Experiment II were more active than controls, but contrary to expectation, amphetamine had no significant effect. Since, in some situations, the effects of amphetamine upon behavior are rate dependent, the possibility exists that the discrepancy between Experiments I and II reflects differences in initial rate of responding. The present experiment tests this possibility in the open field. Previous experiments

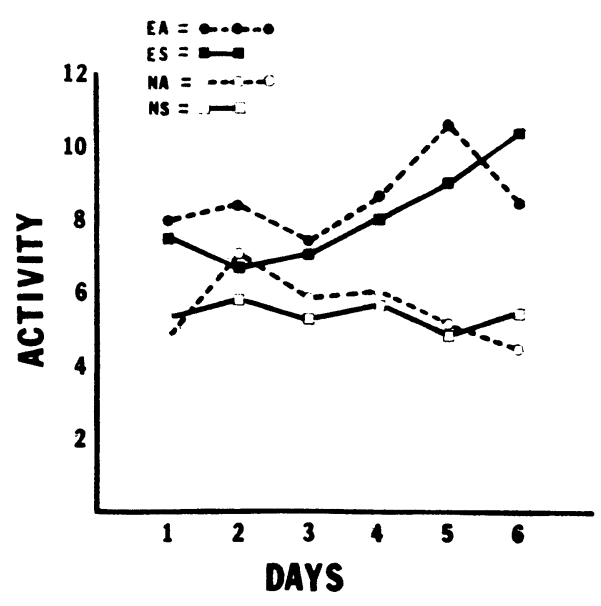

Figure 2. Mean photocell-box activity scores for each group of Experiment II. Scores are in arbitrary units, legend as in Figure 1.

(Dyer \& Weldon, 1975) have examined the open-field activity of blind and normal mice from six different strains. Of those strains tested, normal $\mathrm{BALB} / \mathrm{cj}$ mice were found to be least active, and blind DBA/2J were found to be most active. In addition, DBA $/ 2$ mice are more reactive to amphetamine than BALB/c mice (Davis et al., 1974). In the present experiment, blind and normal $\mathrm{BALB} / \mathrm{cj}$ and $\mathrm{DBA} / 2 \mathrm{~J}$ mice were given either amphetamine or saline and studied in the open field.

\section{Method}

Design. Animals of each strain were randomly assigned to one of four groups, and the experiment was performed as two separate 2 by 2 factorials with Amphetamine Treatment and Enucleation as the factors. The groups were composed the same as in Experiments I and II.

Animals and surgery. Sixty male BALB/cj and 32 male DBA/2J mice obtained from the Jackson Laboratories were housed, fed, and operated upon as described in Experiment $I$.

Apparatus. Testing occurred in a $1.22 \times 1.22 \mathrm{~m}$ plywood open field, ruled with black lines into 16 equal squares and sprayed with urethane for ease of cleaning.

Procedure. Animals were injected with the appropriate solution, either $10 \mathrm{mg} / \mathrm{kg}$ of d-amphetamine or saline, and returned to their home cages for $30 \mathrm{~min}$. Subsequently they were placed in a corner square of the open field, and the number of entries into different squares was recorded for $2 \mathrm{~min}$, an interval previously shown long enough to observe blind vs. normal activity differences (Dyer \& Weldon, 1975). The apparatus was cleared of feces and urine by wiping with a damp rag after occupation by each mouse.

Results

The results are shown in Figure 3, which shows that in all cases blindness increased activity, but amphetamine only appeared to affect the blind DBA/2J mice. A 2 by 2 analysis of variance performed for each strain showed that for $B A L B / c j$ mice there was a significant effect of enucleation $(p<.001)$, but no significant effect of drug $(p>.10)$, nor was there a Drug by Enucleation 


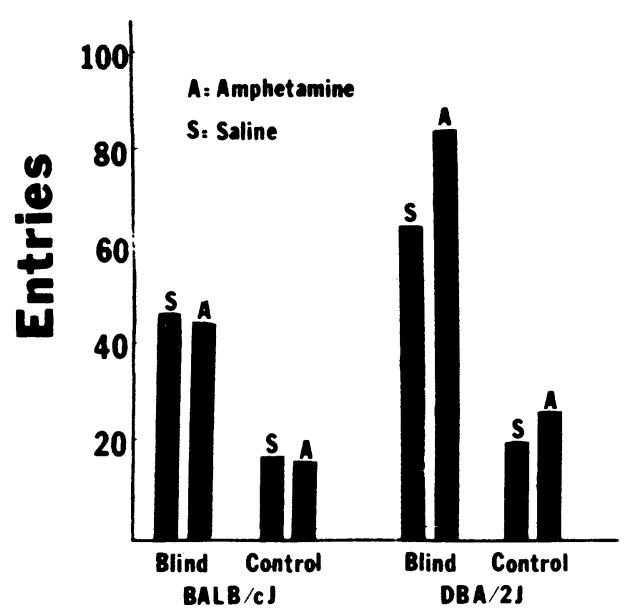

Figure 3. Mean open-field activity scores for blind and normal DBA/2J and BALB/cj mice injected with saline or amphetamine.

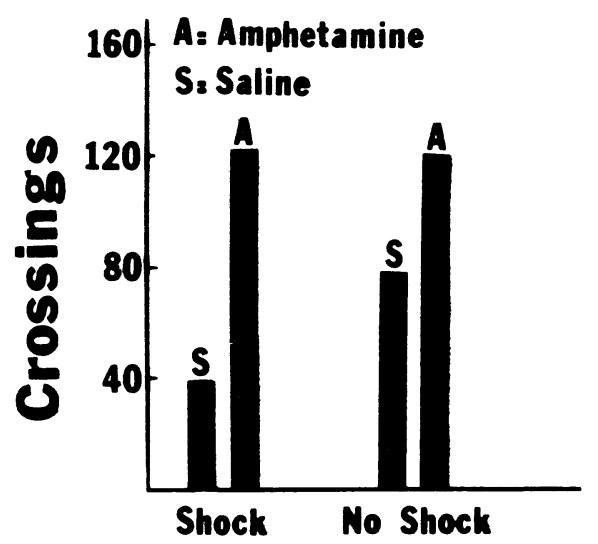

Figure 4. Mean shuttlebox crossings for amphetamine- or saline-injected BALB/cj mice, with or without shock.

interaction $(p>.10)$.

The results were not as clear for the $\mathrm{DBA} / 2 \mathrm{~J}$ strain. Again, there was a significant effect of Enucleation $(\mathrm{p}<.001)$ and no significant Drug by Enucleation interaction $(p>10)$. However, the main effect of Drug approached significance $(F=3.37, \mathrm{df}=1 / 28$, $.05<\mathrm{p}<.10)$.

\section{EXPERIMENT IV}

In Experiment I, amphetamine had an effect upon activity, which for the enucleated animals were most apparent on Day 1. Enucleation, on the other hand, only produced changes in activity after several days of training. Experiments II and III found immediate effects of enucleation, but no effect of amphetamine. Previous experiments (Dyer, 1971; O'Hara \& Dyer, 1974), when taken together, suggest that the presence of shock may decrease the difference between blind and normal guinea pigs. This probably accounts for the initial similarity between the blind and normal mice of Experiment I.
The presence or absence of shock might also account for the different effect of amphetamine in Experiment I compared to Experiments II and III. The present experiment tests this possibility.

\section{Method}

Animals, design, and apparatus. Sixty male BALB/cj mice were obtained, housed, and fed as in Experiment l. Animals were randomly assigned to one of four groups in a 2 by 2 factorial design, with Amphetamine vs. Saline and Shock vs. No Shock as factors.

The apparatus was a mouse shuttle cage identical to that described for Experiment I.

Procedure. Thirty minutes after the appropriate injection, each mouse was placed in the shuttlebox for $10 \mathrm{~min}$, and the number of crossings were recorded. In addition, for those mice in the amphetamine-shock or saline-shock groups, a total of 10 footshocks of . $3 \mathrm{~mA}$ ac were delivered at an approximate rate of $1 / \mathrm{min}$. Each shock lasted for $3 \mathrm{sec}$ but could be escaped by crossing to the opposite side of the box. No warning signal was used.

\section{Results}

The results are shown in Figure 4, which shows that amphetamine-treated animals were not affected by shock, and that shock apparently suppressed the activity of saline-injected mice. Analysis of variance partly confirms this description. The effect of Drug was significant $(p<.001)$, but the effects of Shock and the Shock by Drug interaction were not significant. Planned comparisons between the amphetamine shock and saline shock groups revealed a significant difference $(p<.01)$, but the difference between amphetamine no-shock and saline no-shock groups was not significant $(\mathrm{p}>.05)$.

\section{GENERAL DISCUSSION}

The main results of these experiments are summarized in Figure 5, which shows that, in BALB/cj mice, a $10-\mathrm{mg} / \mathrm{kg}$ dose of amphetamine is most effective in changing activity under highly stressful conditions (shock). Blindness appears most effective in producing activity changes under less stressful conditions, since the presence of shock in Experiment I eliminates the blind vs. normal difference

\begin{tabular}{|c|c|c|}
\hline EXPERIMENT & NO SHOCKS & shocks \\
\hline $\begin{array}{l}\text { I Two-waY } \\
\text { AVOIDANCE }\end{array}$ & & $\begin{array}{l}\text { ENUC: WO EFFECT } \\
\text { AMPHET: MYPEARACTIVE }\end{array}$ \\
\hline I PHOTOCELL BOX & $\begin{array}{l}\text { ENUC: HYPERACTIVE } \\
\text { AMPNET: WO EFFECT }\end{array}$ & \\
\hline II OPEN FIELD & $\begin{array}{l}\text { ENUC: GYPERACTIVE } \\
\text { AMPHET: NO EFFECT }\end{array}$ & \\
\hline $\begin{array}{l}\text { I shuttlesox } \\
\text { Activity }\end{array}$ & АМРHET: МO EFFECT & AMPUET: MYPERACTIVE \\
\hline
\end{tabular}

\section{DATA FROM FIRST DAY OF EACH EXPERIMENT}

Figure 5. Summary of Experiments I-IV, illustrating comparative effect of shock on enucleated- or amphetamine-treated animals. Data from Experiments I and II represent only the 1st day of testing. 
on the first few days of training. Thus amphetamineinduced hyperactivity and blindness-induced hyperactivity are dissociable. Furthermore, inspection of Figure 4 raises the possibility that amphetamine produced its activity changes by preventing the suppressing influence of severe stress.

It is, of course, risky to make general statements concerning the effects of amphetamine based upon this study. The absence of any dose/response data makes it impossible to determine whether adding shock shifts the dose/response curve or amplifies it. However, the main thrust of the study is to show that a constant dose of amphetamine produces more activity in tasks with shock, but that a large number of shocks decreases activity of blind mice, and this finding is not weakened by the absence of dose/response data. A more serious limitation is that $\mathrm{BALB} / \mathrm{c}$ mice are less reactive to amphetamine than other strains (Davis et al., 1974) and that they possess some anomalous forebrain characteristics (Wahlstein, 1974).

In conclusion, although $\mathrm{BALB} / \mathrm{c}$ mice are generally less reactive to the locomotor effects of amphetamine than they are to the locomotor effects of blindness, amphetamine does seem to protect both normal and blind mice from the suppressing effects of shock. On the other hand, blindness does not appear to protect the animals against the suppressing effects of shock.

\section{REFERENCES}

Davis, W. M., Babbini, M., Pong, S. F., King, W. T., \& WhITE, C. L. Mobility of mice after amphetamine: Effects of strain, aggregation, and illumination. Pharmacology, Biochemistry and Behavior, 1974, 2, 803-809.

DYER, R. S. Influences of the visual system upon two-way avoidance learning in the guinea pig. Journal of Comparative and Physiological Psychology, 1971, 76, 434-440.

Dyer, R. S., \& Hammond, M. Effects of enucleation in retinal degenerate mice. Physiology and Behavior, 1975, 14, 207-211.

Dyer, R. S., Hammond, M., Weldon, D., \& Booker, T. Influence of enucleation upon two-way avoidance behavior of rats, hamsters, chinchillas and BALB/cJ mice. Physiology and Behavior, 1975, 14, 211-216.

DYER, R. S. \& Weldon, D. Blindness-induced hyperactivity in several strains of mice. Physiology and Behavior, 1975, $15,439-441$.

KePPEL, F. Design and analysis. Englewood Cliffs, N.J: Prentice-Hall, 1973.

KIRK, R. E. Experimental design: Procedures for the behavioral sciences. Monterey, Calif: Brooks/Cole, 1968.

O'HARA, M. P., \& DYER, R. S. Locomotor exploratory activity in blind and normal guinea pigs. Physiology and Behavior, 1974, 13, 701-702.

WAHLSTEIN, D. Heritable aspects of anomalous myelinated fibre tracts in the forebrain of the laboratory mouse. Brain Research, 1974, 68, 1-8.

(Received for publication September 4, 1975; accepted October, 17, 1975.) 